\title{
Research on the Development of Rural Electric Merchants in the Mode of "Internet + Agriculture"
}

\author{
Zhang Xuqi
}

Xi'an International University, Business school, Xi'an, Shaanxi ,China

Keywords: Development, Rural Electric Merchants, "Internet + Agriculture"

\begin{abstract}
China is a big agricultural country, the development of agriculture had a very important impact on Chinese economic development. In order to promote the development of agriculture, we must actively seek innovation and improve the intelligent, ecological and precise level of agricultural production. Internet + agriculture model refers to the use of Internet technology to improve the scientific and technological content of all aspects of agriculture, to promote the optimization of the production chain of traditional agriculture, so that the agricultural industry structure achieve the efficient use of agricultural resources as soon as possible to break through the traditional agricultural model obstacles and adapt to the development of modern new agriculture.
\end{abstract}

\section{Introduction}

According to statistics, Chinese rural areas have up to 600 million consumer groups and more than 10 trillion market potential, in 2014 the national rural online shopping total of about 200 billion RMB. To "Internet + agriculture" as the main line, the construction of rural e-commerce integrated service platform has become a new trend in the development of rural electricity business.

In 2010, the State Council has issued "the State Council on the development of e-commerce to accelerate the development of new economic power of the views of" the State Council on actively promoting the "Internet +" action guidance "'" General Office of the State Council on promoting rural e-commerce to accelerate the development of guidance " And made it clear that the rural e-commerce market system, which will be unified and open in an all-round, competitive and orderly, honest and law-abiding, safe, reliable and green environment, will be fully integrated in 2020 to promote the integration of e-commerce and the three industries and promote rural employment Market, promote rural poverty alleviation and development.

With the introduction of relevant policies at the national level, rural electric business has been given more and more important significance, it is not just an economic industry, it is a people's livelihood topic, to explore the development of rural electricity business is imperative.

\section{The Chinese Current Development of Rural Electricity Providers}

In recent years, China has continuously strengthened the construction and development of agricultural electricity platform, the number of agricultural sites also grow at a faster rate, agricultural enterprises understand the importance of the Internet economy, one after another to join the major business platform. According to the current development of rural electricity business, we can see that Chinese agricultural electricity business model is not yet mature and looking for the current agricultural economic development and production needs of the agricultural electricity business model is the need to solve the problem. Practice shows that the use of advanced technology, such as network technology, information technology and communication technology must be strengthened in order to promote the development of agricultural electricity providers. According to the actual operation, it is obvious that the important information from the national level is often more than that in the following aspects, mainly in the following aspects, such as important, can provide guidance data cannot be farmers to obtain and use, agricultural information service platform function there are flaws, rural communication network construction has not kept pace with the development of the times, 
agricultural electricity business talent is scarce, farmers do not understand the operation of agricultural electricity business model. These factors are hampered by the development of rural electricity providers.

\section{The Main Problems in Current Development of Rural Electricity Business}

The penetration rate of rural Internet is low. According to the survey, Chinese rural Internet penetration rate of less than $20 \%$, while the urban Internet penetration rate of nearly $50 \%$, and with the development of the times, rural Internet penetration and urban Internet penetration rate gap is more and more obvious. Thus, compared to urban and rural Internet penetration rate is significantly lower, and the gap between the two more and more obvious. The lack of efficient use of Internet technology in rural areas and the lack of a rational allocation of infrastructure have limited the further development of rural electricity providers.

The Overall consumption concept of farmers is relatively backward. Most of the rural areas are located in remote locations, low level of information technology, only a small number of rural areas can access to new consumer ideas. E-commerce transactions are mainly on-line, and with the effective combination of offline transactions, and its traditional trading model there is a clear difference. Farmers have become accustomed to the traditional trading model and it is difficult to accept the new trading model. To allow farmers to recognize online transactions, it takes a long time to change the traditional concept of consumption of farmers. For rural areas where economic conditions are better, farmers are able to change their minds quickly and accept new things online. And the economy is more backward in rural areas need to change the traditional concept of consumption in order to adapt to the social commodity economy development situation.

Lack adequate rural electrician service talents. In order to promote the development of rural electric business, it is necessary to build rural electrician personnel, to ensure that the team has a strong professional, and have a reasonable structure and high quality. Rural electrician personnel team construction, the same will involve more departments and a wider range of areas. At present, the lack of agricultural information collection and analysis of personnel, resulting in valuable information resources development and utilization efficiency is very low. In addition, most young people in rural areas to go out to study or work, resulting in the local young and middle-aged is very rare, rural electricity service personnel are mainly in the elderly, the lack of understanding of new knowledge and new skills, computer networks and other advanced technology is difficult to grasp, the most important thing is that this group of learning ability is poor. As rural areas do not have sufficient talent, leading to the popularity of rural electricity and development is limited.

Lack of perfect rural logistics and distribution network. Rural areas have the following characteristics, that is, a wide range of population living, mostly in remote mountainous areas, traffic inconvenience, the rural electricity business logistics and obstruction. For now, most of the third party logistics company's logistics and distribution network can only reach the county cannot reach the remote mountain village, resulting in the mountain village farmers modern logistics needs are not met. In order to promote the agricultural products produced by farmers to better circulate in the market, to maximize the benefits of farmers, we must strengthen the rural logistics and distribution network construction and improvement, so as to promote the rapid development of rural electric business.

\section{The Development Countermeasures of Current Rural Electricity Business in the Internet + Agriculture Model}

Speed up the construction of rural information infrastructure. Improve the network supporting facilities, is to improve the network penetration of an important prerequisite. Improve the rural network infrastructure construction, focusing on the basic network planning and coverage of the building, to promote the popularity of cable television and telephone, to promote the level of broadband services to achieve effective use of cost control. Moreover, the government should 
provide strong support in terms of capital and technology to promote rural areas as soon as possible to build a sound rural information website and township-level electricity providers website, to strengthen the publicity on rural electricity providers, so that farmers more active participation To the electricity business market, so that they better and more convenient to understand the electricity sales platform for the sales model, feel the unique advantages of electricity providers to adjust the traditional agricultural structure and trading model, conform to the development of e-commerce situation.

Improve the rural electrician business education and training system. The rural government needs to strengthen the publicity and education of the rural Internet knowledge with the relevant educational departments, promote the popularization of rural Internet knowledge, arrange special trainers to guide farmers to use computers, mobile phones and other equipment, focusing on training farmers to use the electricity platform to retrieve information and transactions and settlement. The government also needs to strengthen the advantages of promoting electricity providers, so that farmers know that electric business has a good development prospects, so that farmers benefit from the electricity business transactions. To improve the enthusiasm of farmers to engage in electricity transactions, to eliminate the prejudice of farmers to electricity, to help them a comprehensive and objective understanding of electricity providers, and through the electricity business platform to benefit, so that farmers more recognized and accepted the new business, and to High enthusiasm to participate in the knowledge of electricity providers to learn and create the business platform.

Establish rural electrical distribution network with integrated supply and logistics. The development of rural electric business, the focus is on the development of rural markets. We must promote the integration of logistics and supply construction, rural electricity business to promote the development of agricultural economy. Although relying on foreign capital to invest in agricultural electricity business logistics construction cannot effectively solve the problem, but the rural electric business by virtue of the agricultural commercial logistics self-establishment, to better realize the agricultural stationed in the business platform. The rural electricity business platform to provide agricultural products and services, in order to improve the value of agricultural products, logistics channels must ensure the smooth flow. The perfection of the logistics and distribution system plays a decisive role in the success or failure of the agricultural electricity platform. Therefore, we must improve the supply chain and logistics system, in order to promote rural electric business to get better development.

Ensure the quality of goods and services. The initial stage of the development of rural e-commerce is to use the network to sell the goods to the countryside or to sell the rural native products to the other end of the network to such a two-way circulation, connecting the rural and urban important media is the goods and service. Therefore, to ensure and improve the quality of goods and services is the electricity business must pay attention to the problem. On the one hand, the electricity business to continue to develop the rules to carry out severe anti-counterfeiting activities, so that the flow of products into the rural areas can be guaranteed, resulting in word of mouth effect. On the other hand, the electricity business should be deeply aware of the characteristics of rural industries and products, and guide rural electricity to the characteristics of business development, not only to avoid the homogeneity of agricultural products, but also improve the competitiveness of agricultural products, resulting in brand effect.

Stimulate potential customers in rural areas. Although many rural population in China, but most of the rural youth to go out to study or work, stay in the rural areas are mostly left behind women, left-behind children, empty nest elderly. Most of them are relatively unfamiliar to the Internet, for online shopping or mobile phone shopping is holding a skeptical attitude, to stimulate the consumption capacity of these potential customers, is conducive to electricity to open up the rural market. To this end, you can proceed from the following two aspects, one is to increase publicity efforts to regularly promote the good products and services to the countryside, to effectively promote the health of life, improve the quality of life of the products to the eyes of the villagers, online shopping product quality doubts, and seven days no reason to return policy and other affordable policies introduced to the villagers, so that they worry about online shopping, and slowly change their 
spending habits. Second, the development of rural finance, Union Bank to the countryside free of charge for the villagers for bank cards, open online payment, mobile payment and other functions, and professionals to train the villagers to teach them how to use the Internet or mobile phone convenient and fast in the network on the shopping.

Coordinate the relationship between the government and the market. Rural electricity business in the development process, the Government should adhere to the concept of service, in the public welfare and business combination of long-term development mechanism, requiring the relevant departments to actively cooperate to ensure that the use of rural electricity farmers to get fair market treatment. The government also needs to coordinate the work of operators and service providers at all levels to make reasonable adjustment of profit margins, the use of scientific operation and development model. In addition, it is necessary to strengthen the support of rural electrician development in the area of legal policy, so as to effectively solve the problems that cannot be solved in the past, open up a broad road for the development of rural electrician, and effectively coordinate the government, enterprises, farmers and consumers relationship.

Strengthen the use of agricultural data resources. Large data has a significant impact on social development and will be applied more widely in future societies. At present, due to the existence of horizontal and vertical barriers, although the government has a wealth of data resources, but the utilization of these resources is low and it cannot reflect the value of data resources. Government departments need to update their ideas, correct working attitude, to promote the effective use of these agricultural data resources for the construction of rural electricity platform to provide information and data support. The government needs to adhere to the principle of openness, the establishment of large data management agencies, improve the relevant laws and regulations, to promote the effective management and utilization of data.

\section{Conclusion:}

The development of rural electricity business in the "Internet + agriculture" mode, the key lies in the integration. With the continuous development of Internet technology, its function is more and more powerful. The "Internet + agriculture" is to promote the powerful function of the Internet in the agricultural production of all aspects of the effective integration. This is an effective integration process of advanced information technology and the agricultural development, we need to strengthen technological innovation and take appropriate development measures for the existing problems in the current development of rural electricity in order to promote the rural electric business in "Internet + agriculture" mode.

\section{References}

[1] B. N. Ma, A study on the development system of rural electric business in the mode of "Internet + agriculture", J. Heilongjiang Science and Technology Information. 44 (2010) 146-147.

[2] H.X.Zeng, Opportunities and challenges for rural electric business development under the background of "Internet + agriculture", J. Trade Finance. 18(2005) 55-57.

[3] J.H.Xue, Internet + Agriculture: difficulties and breakthroughs in the development of rural electric merchants, J. Economist, 32(2012) 189-190.

[4] Y.J.Qi, "Internet + agriculture" to build a new path for the development of rural e - commerce in China, J, Business Economics Research, 4(2007) 38-40.

[5] Y.M.Tian, Analysis on the present situation and countermeasures of rural electricity business in China, J. Northern Trade, 9(2013) 142-150. 